\title{
Tratamento precoce da mordida aberta: $O$ que é importante saber?
}

\author{
Early open bite treatment: What is important to know? \\ Tratamiento temprano de mordedura abierta: ¿Qué es importante saber?
}

Recebido: 22/11/2021 | Revisado: 01/12/2021 | Aceito: 05/12/2021 | Publicado: 14/12/2021

\author{
Camilla de Aguiar Leal Gomes \\ ORCID: https://orcid.org/0000-0003-4636-7986 \\ Centro Universitário Mário Pontes Jucá, Brasil \\ E-mail: millafisio13@gmail.com \\ Bárbara Camila Ferreira da Silva \\ ORCID: https://orcid.org/0000-0002-1443-5705 \\ Centro Universitário Mário Pontes Jucá, Brasil \\ E-mail: baby_ba-2011@hotmail.com \\ Daniella Mascarenhas Calixto Barros \\ ORCID: https://orcid.org/0000-0002-6729-4897 \\ Centro Universitário Mário Pontes Jucá, Brasil \\ E-mail: daniela.mascarenhas@umj.edu.br
}

\begin{abstract}
Resumo
O objetivo deste estudo foi avaliar os principais métodos de tratamento para mordidas abertas anteriores, dentoalveolares ou esqueléticas, levando em consideração, as vantagens e as complicações envolvidas durante essas fases de tratamento para a estabilização da mordida das crianças durante sua fase de desenvolvimento craniofacial. Os estudos selecionados para compor a revisão de literatura publicados nos últimos 10 anos nas seguintes bases de dados da área da saúde: PubMed/Medline, Scopus, LILACS, SciELO e Cocrhane. Os principais resultados demonstraram que o principal objetivo do tratamento precoce da mordida aberta anterior é a eliminação dos hábitos bucais deletérios, fazendo uso de variados aparelhos e dispositivos que foram primariamente eficazes na diminuição da sobremordida negativa, na melhoria do posicionamento da língua e dos dentes, além de alterações fisiológicas esqueléticas. Isso permite concluir que os metódos empregados para o tratamento precoce da mordida aberta anterior são de grande eficácia para aumentar a sobremordida e proporcionar as funções fisiológicas para o sistema estomatognático com estabilidade a longo prazo dessas alterações.
\end{abstract}

Palavras-chave: Saúde da criança; Ortodontia; Mordida aberta.

\begin{abstract}
The aim of this study was to evaluate the main treatment methods for anterior, dentoalveolar or skeletal open bites, taking into account the advantages and complications involved during these treatment phases for the stabilization of the bite of children during their craniofacial development phase. The studies selected to compose the literature review published in the last 10 years in the following databases in the health area: PubMed/Medline, Scopus, LILACS, SciELO and Cocrhane. The main results showed that the main objective of early treatment of anterior open bite is the elimination of harmful oral habits, making use of various devices and devices that were primarily effective in reducing negative overbite, improving the positioning of the tongue and teeth, in addition to skeletal physiological changes. This allows us to conclude that the methods used for the early treatment of anterior open bite are very effective in increasing overbite and providing physiological functions for the stomatognathic system with long-term stability of these alterations.
\end{abstract}

Keywords: Child health; Orthodontics; Open bite.

\section{Resumen}

El objetivo de este estudio fue evaluar los principales métodos de tratamiento de la mordida abierta anterior, dentoalveolar o esquelética, teniendo en cuenta las ventajas y complicaciones que implican durante estas fases de tratamiento para la estabilización de la mordida de los niños durante su fase de desarrollo craneofacial. Los estudios seleccionados para componer la revisión de la literatura publicada en los últimos 10 años en las siguientes bases de datos del área de la salud: PubMed / Medline, Scopus, LILACS, SciELO y Cocrhane. Los principales resultados mostraron que el principal objetivo del tratamiento temprano de la mordida abierta anterior es la eliminación de los hábitos bucales nocivos, haciendo uso de diversos dispositivos y dispositivos que fueron principalmente efectivos para reducir la sobremordida negativa, mejorando el posicionamiento de la lengua y los dientes, además a los cambios fisiológicos esqueléticos. Esto nos permite concluir que los métodos utilizados para el tratamiento temprano de la mordida abierta anterior son muy efectivos para aumentar la sobremordida y proporcionar funciones fisiológicas para el sistema estomatognático con estabilidad a largo plazo de estas alteraciones.

Palabras clave: Salud del niño; Ortodoncia; Mordida abierta. 


\section{Introdução}

A mordida aberta anterior é uma má-oclusão caracterizada pela ausência de oclusão dentária anterior, não existindo o contato vertical de forma fisiológica entre os incisivos superiores e inferiores, existindo assim, uma sobremordida negativa. É considerada um dos problemas de oclusão com maior comprometimento estético e funcional. É uma condição ortodôntica considerada altamente incidente, principalmente entre crianças, e durante a dentição mista, isso se deve ao fato de os dentes e os ossos serem propensos a forças e pressões da musculatura, que podem causar modificações na posição dentária. Essa perda de equilíbrio do sistema estomatognático que dá origem a uma má-oclusão pode ser ocasionada por inúmeros fatores etiológicos. (Artese et al., 2011; Leite et al., 2016; Núñez et al., 2014; Rosa et al., 2019).

Levando em consideração essa característica multifatorial da mordida aberta anterior, essa condição aparece principalmente em decorrência de hábitos bucais deletérios, e especial a sucção digital, presença de tecidos linfoides hipertróficos, respiração bucal, fonação e deglutição atípicas, além de postura anormal da língua durante o repouso. Apesar de muitos desses fatores não serem bem estabelecidos quanto ao nível de envolvimento com a má-oclusão em questão, os hábitos deletérios são os que mais afetam o equilíbrio entre o sistema estomatognático. Logo, esses casos associados a disfunções dos hábitos bucais são definidos como sendo mordidas abertas dento-alveolares, onde os as proporções esqueléticas são relativamente normais. Em menor frequência, encontram-se as mordidas abertas esqueléticas, onde existem modificações entre as dimensões esqueléticas e faciais, durante o desenvolvimento ósseo do crânio. Essa má-oclusão, no geral, possuem uma resolução mais difícil e tende a recidivar com o passar do tempo. (Artese et al., 2011; Koletsi et al., 2018; Mousa et al., 2021; Pisani et al., 2016).

Como a presença da mordida aberta anterior pode prejudicar a fonação, alimentação e irrupção dos elementos dentários permanentes, esse distúrbio necessita ser tratado o mais cedo possível, para restabelecer o equilíbrio da musculatura facial, do posicionamento dos dentes e do crescimento craniofacial. Nos casos dento-alveolares atribuídos à presença de hábitos deletérios, como sucção não nutritiva, o tratamento precoce diz respeito a eliminação do hábito deletério. A ausência desses hábitos é capaz de proporcionar a autocorreção da mordida aberta em crianças jovens. Em outros casos, a autocorreção não se concretiza, e nessas situações, junto aos casos de mordidas abertas esqueléticas, inúmeras abordagens ortodônticas interceptativa podem ser utilizadas efetuar o fechamento estável da mordida aberta e melhorar o equilíbrio facial e esquelético da criança. (Artese et al., 2011; Lione et al., 2020; Mucedero et al., 2017; Mousa et al., 2021).

Os principais protocolos de tratamento abordados nas clínicas odontológicas incluem o uso de aparelhos e dispositivos funcionais fixos e/ou removíveis, também fazendo uso de associações desses aparelhos, com o intuito de permitir a correção da má-oclusão e trazer estabilidade da mordida para a criança durante o seu desenvolvimento. A escolha dos dispositivos e o tempo de tratamento deve levar em consideração os fatores etiológicos envolvidos na mordida aberta anterior, e as características de cada criança, evitando complicações durante o seu tratamento. (Pisani et al., 2016; Rossato et al., 2021). Assim, ponderando a importância do tratamento precoce dessa má-oclusão, o objetivo deste trabalho é avaliar os principais métodos de tratamento para mordidas abertas anteriores, dento-alveolares ou esqueléticas, levando em consideração, as vantagens e as complicações envolvidas durante essas fases de tratamento para a estabilização da mordida das crianças durante sua fase de desenvolvimento craniofacial.

\section{Metodologia}

Esta revisão de literatura foi delineada através dos princípios e diretrizes do PRISMA, definindo com precisão etapas cruciais para a escolha dos trabalhos a serem utilizados no presente estudo. (Moher et al., 2009; Hermont et al., 2021). Pensando nisso, foi definido inicialmente os critérios empregados para buscar os estudos que correspondam aos objetivos da revisão. Os critérios de inclusão de trabalhos foram: artigos publicados entre janeiro de 2011 e junho de 2021; estudos escritos 
na língua portuguesa, inglesa e espanhola; trabalhos que avaliem que estudem as principais formas de tratamento para mordidas abertas anteriores; os que comparem métodos e associações de tratamentos ortodônticos usados para o tratamento precoce das mordidas abertas; e avaliações da eficácia dos tratamentos para mordidas abertas dento-alveolares e esqueléticas; e por fim, artigos que abordem tratamentos que não fazem uso de aparelhos ortodônticos. Já os critérios de exclusão são: estudos não disponíveis integralmente para leitura; revisões de literatura; artigos que avaliem tratamentos ortodônticos para outras máoclusões que não sejam a mordida aberta; trabalhos que não demonstrassem as mudanças dento-alveolares e esqueléticas dos tratamentos para mordida aberta anterior; estudos com tratamentos para a prevenção da mordida aberta anterior; e trabalhos com tratamento baseados em aparelhos ortodônticos fixos convencionais.

Com o estabelecimento desses critérios, se buscou elaborar uma estratégia de busca eletrônica que seria inserida nas principais bases de dados da área da saúde. Foram elegidas as seguintes bases para a pesquisa dos trabalhos científicos a serem usados na revisão: PubMed/Medline, Scopus, LILACS, SciELO e Cochrane. Já a estratégia de busca consistiu na escolha dos seguintes descritores DeCS/ MeSH, e termos alternativos unidos a operadores booleanos que englobaram as principais características a serem observadas dentro dos estudos, sendo aplicado os seguintes termos: "Anterior Open Bite" AND "Orthodontics" AND "Early Treatment". Com a aplicação desses termos nas bases de dados, surgiram os artigos publicados que tinham semelhança com a pesquisa realizada, e, a partir disso, é feito de fato a escolha dos estudos específicos para este trabalho. Para isso, foi feita uma leitura inicial dos títulos e resumos dos artigos, pré-selecionando os que estavam de acordo com os critérios estabelecidos. Com isso, foram retirados os artigos duplicados e os que não estavam disponíveis integralmente para leitura. Os demais artigos foram analisados por completo, onde se verificou os que não se encaixavam por completo aos objetivos desta revisão. Finalmente, o restante dos artigos foi utilizado para a composição deste trabalho, onde também foram analisadas manualmente as suas referências, em busca de complementação referencial. Como última etapa, a análise do conteúdo desses artigos, após todas essas etapas de seleção, foi realizada através do auxílio de uma tabela com o resumo dos principais achados contidos nessas publicações, diminuindo os possíveis erros de transcrição de dados.

\section{Resultados}

Ao realizar a pesquisa eletrônica nas bases de dados selecionadas anteriormente, foram encontrados 244 artigos publicados que podiam estar interligados às limitações designadas na metodologia. Com a leitura inicial dos títulos e resumos, foram pré-selecionados 25 estudos. Dentre esse total, 08 foram retirados por estarem duplicados entre as bases de dados pesquisadas, restando 17 estudos viáveis para a presente revisão de literatura. Dessa forma, foi realizada a leitura integral dos artigos, que acarretou em mais 02 estudos excluídos, levando em consideração os critérios de exclusão eleitos outrora. A pesquisa manual das referências não resultou em artigos adicionais para a revisão. Com isso, 15 estudos foram utilizados como base para este trabalho. O processo de seleção dos artigos pode ser observado fluxograma adaptado a partir das diretrizes do PRISMA (Figura 1). 
Figura 1 - Fluxograma adaptado do PRISMA statement for systematic reviews.

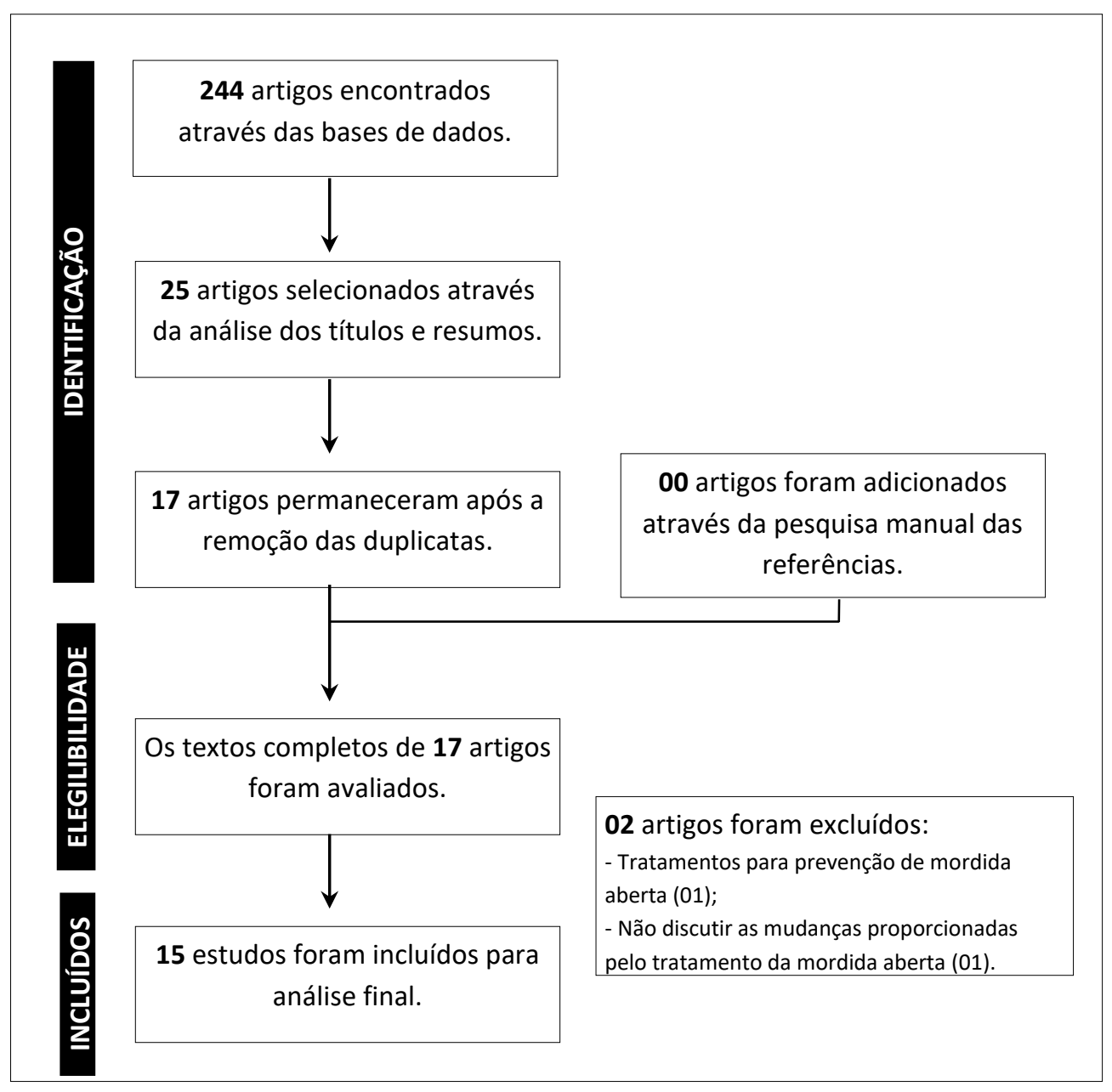

Fonte: Moher et al. (2009).

A Tabela 1, apresentada abaixo, exibe um resumo das principais informações contidas nos estudos selecionados. O primeiro deles foi realizado por Albogha et al., (2015), e teve como objetivo determinar as diferenças entre dois modelos de tratamento para mordida aberta, o uso de blocos de mordida magnéticos e aparelhos de intrusão rápida de molares junto a bloqueios de mordidas posteriores. Ambos tratamentos foram completados em 4 meses, e todos os pacientes exibiram aumentos na sobremordida, porém, somente 9 pacientes obtiveram sobremordida positiva após a remoção dos aparelhos. Ninguém apresentou mordida cruzada posterior ao fim do tratamento, sendo que os blocos de mordida magnéticos demonstraram uma maior diminuição no overjet e na relação intermaxilar, além de maiores retrações dos incisivos superiores. Assim, esses procedimentos foram efetivos na melhora ou no total fechamento de mordidas abertas, não existindo diferenças de qualidade de tratamento entre os dois modelos utilizados no estudo. Porém, os dois aparelhos apresentaram prejuízos à higiene oral das crianças durante o tratamento, necessitando de cuidados especiais na higienização.

Em contrapartida, Canuto et al., (2016) compararam os efeitos de tratamentos para mordida aberta anterior na dentição mista através de esporões linguais colados e convencionais. Todos os pacientes apresentaram pelo menos um hábito oral deletério como, impulsão da língua ou sucção digital. A amostra do estudo foi dividida em grupos semelhantes de aproximadamente 20 para tratamento com esporões colados, convencionais e pacientes não tratados. Os resultados exibiram que ambas as intervenções foram bem aceitas pelos pacientes, sendo que os tratamentos com esporões colados tiveram aceitação maior do que os convencionais, principalmente durante a alimentação e mastigação. $\mathrm{O}$ desconforto relatado com o tratamento foi de, no máximo, 7 dias, e a sobremordida positiva foi alcançada em 16 dos 20 casos e em 16 dos 21 casos de 
pacientes que usaram esporão colado e convencional, respectivamente, durante 12 meses de tratamento. Também foi visto três casos de correção espontânea da mordida aberta anterior.

Similarmente, Dias et al., (2019) apresentou um caso de mordida aberta anterior grave tratado através de esporões linguais colados. O paciente apresentou hábito de sucção de chupeta e mamadeira, e selamento labial não passivo. O tratamento com os esporões demonstrou uma sobremordida positiva cinco meses após o início do uso do aparelho, e com a finalização do procedimento após 13 meses, foi gerada uma sobremordida final de 1,8 $\mathrm{mm}$. O paciente foi acompanhado por 2,15 anos e apresentou arcadas dentárias alinhadas com sobremordida normal e irrupção adequada dos dentes permanentes. Por fim, o aparelho em questão não causou desconforto ou lesões orais ao paciente durante o tratamento.

Anteriormente, Dyck et al., (2016) investigou os efeitos da terapia miofuncional no comportamento da língua em crianças com mordida aberta anterior. 68,2\% das crianças não possuíam oclusão entre os dentes anteriores, e todas as crianças apresentavam padrões não-fisiológicos de deglutição e problemas na posição da língua em repouso. Dessa forma, o estudo demonstrou que ocorreu um aumento da postura fisiológica da língua em repouso e na deglutição após a terapia miofuncional, e após 6 meses do fim da terapia, essas crianças apresentaram contato entre os incisivos inferiores e os seus antagônicos ou com o palato em si. A posição normal da língua permitiu a irrupção fisiológica dos dentes permanentes. Porém, os resultados não foram considerados estatisticamente significativos.

De maneira distinta, foi realizado um trabalho por Ferreira et al., 2012 objetivando analisar a estabilidade das alterações dento-alveolares e esqueléticas produzidas pelo uso de aparelho removível com grade palatina associado ao suporte para queixo de alta tração em indivíduos com mordida aberta anterior tratados por 12 meses. Após o acompanhamento de 15 meses dos resultados do tratamento, ocorreram apenas pequenas alterações dento-esqueléticas e dos tecidos moles, demonstrando que esse tratamento parece ser muito estável. De 19 crianças tratadas com o aparelho, 12 delas tiveram uma melhora na sobremordida, e 7 dessas crianças apresentaram diminuição da sobremordida, sendo que somente 1 paciente apresentou recidiva da má oclusão após o tratamento. Já as crianças não tratadas também apresentaram um aumento da sobremedida, porém, a má oclusão permaneceu constante a longo prazo, sendo necessária intervenções em 12 de 19 crianças que não foram tratadas neste estudo, e só 1 delas obteve uma melhora espontânea da má oclusão. Após o tratamento de 12 meses com o aparelho, as crianças apresentaram uma sobremordida média de $0,94 \mathrm{~mm}$, e as que não foram tratadas tinham um valor médio de $-2,66 \mathrm{~mm}$ de sobremordida.

Por sua vez, Insabralde et al., (2016) avaliaram os efeitos dento-esqueléticos produzidos através do tratamento com grades palatinas removíveis, esporões linguais colados e mentoneiras para mordida aberta anterior em crianças. Todos os pacientes possuíam similaridade entre as variáveis cefalométricas antes do tratamento selecionado para cada paciente. Os pacientes foram tratados com diferentes protocolos e associações de tratamentos. Foram avaliados os seguintes tratamentos: uso de grades palatinas removíveis associadas às mentoneiras; uso de esporões linguais colados associados com a mentoneira; e somente a utilização das mentoneiras. Os resultados demonstraram que os pacientes tratados com as grades palatinas junto às mentoneiras apresentaram um maior aumento da altura facial anterior e da sobremordida, bem como maior inclinação palatina e retrusão dos incisivos superiores, quando comparado às demais formas de tratamento efetuadas. $\mathrm{O}$ uso dos esporões linguais junto às mentoneiras também demonstraram bons valores na sobremordida e nas modificações dos incisivos superiores, recebendo destaque sobre o uso isolado das mentoneiras, que acabou não produzindo um bom controle da altura facial vertical. Apesar disso, todas as formas de tratamento exibiram aumentos favoráveis na sobremordida, sendo que 97,5\% dos pacientes tratados com as grades palatinas corrigiram a mordida aberta anterior, assim como $84,5 \%$ dos pacientes que usaram os esporões também trataram a má-oclusão. Somente $48,8 \%$ dos que usaram apenas as mentoneiras resolveram o problema, e 53\% dos pacientes que não foram tratados tiveram resolução espontânea do problema em um período de um ano de acompanhamento. 
No mesmo ano, Leite et al., (2016) avaliaram o efeito de grades palatinas fixas e esporões linguais colados no tratamento precoce de mordidas abertas anteriores. Assim, as crianças tratadas com grades palatinas fixas obtiveram os maiores valores de aumento na sobre mordida, com 3,95 mm, em comparação aos pacientes tratados com esporões linguais $(3,07 \mathrm{~mm})$ e àqueles que não receberam tratamento $(2,33 \mathrm{~mm})$. Porém, esses valores não foram considerados estatisticamente significativos. Também foi possível observar que, apesar de o grupo que não foi tratado ter apresentado aumento nos valores de sobremordida, somente as crianças tratadas com as grades palatinas e os esporões demonstraram valores médios de sobremordida positivos, fazendo com que esses métodos sejam considerados eficazes para a correção da mordida aberta anterior. Dessa forma, a idade média de 08 anos foi considerada pelos autores como um dos melhores momentos para a intervenção e tratamento da mordida aberta, uma vez que somente a interrupção dos hábitos deletérios nessa idade não garantem a reversão da má-oclusão de forma natural, já que somente três pacientes não tratados apresentaram melhoras sem a realização de intervenções.

Mais tarde, Lione et al., (2020) buscaram analisar as modificações mandibulares em crianças com mordida aberta anterior através do tratamento com expansão rápida da maxila junto a bloqueios de mordidas, e uso de Quad Helix com grade palatina. Ambos os tratamentos duraram em média um ano para que fosse alcançada uma sobremordida positiva, sendo que os pacientes tratados através da expansão rápida da maxila e bloqueio de mordida demonstraram boa cooperação durante o período de tratamento em 70,6\% da amostra. Também se notou que 12 crianças tratadas com expansão rápida e 11 tratadas com Quad Helix necessitaram de uma segunda fase de tratamento com aparelhos ortodônticos fixos convencionais para finalizar a oclusão corretamente. Dessa forma, o uso de expansão rápida da maxila junto aos bloqueios de mordida contribuiu para corrigir os problemas esqueléticos verticais e alongar o ramo mandibular. Porém, a associação do Quad Helix e da grade palatina não causou modificações esqueléticas e mandibulares, apesar de permitir que os dentes desenvolvessem uma relação adequada, permitindo a correção da mordida aberta.

De modo semelhante, Mousa et al., (2021) analisaram a eficácia do Bionator de mordida aberta e do plano de mordida posterior removível com suporte de língua como intervenções para a correção precoce de mordidas abertas esqueléticas, objetivando limitar o crescimento craniofacial vertical excessivo das crianças com a má-oclusão. Ambas intervenções demonstraram aumento na sobremordida, entretanto, as crianças tratadas com Bionator de mordida aberta tiveram maior valor de aumento, com 4,91 mm, em comparação ao uso do plano de mordida posterior removível com suporte de língua, com 3,43 $\mathrm{mm}$. Apesar disso, as duas modalidades analisadas produziram alterações esqueléticas semelhantes. Observou-se ainda a ocorrência de ulceração e irritação da mucosa em 10\% da amostra dos dois modelos de tratamento.

Anteriormente, Mucedero et al., (2017) estudaram os resultados de tratamentos com Quad Helix e grade palatina, e arco palatino associado ao capacete de alta tração e protetor labial, para pacientes com mordida aberta anterior. Todos os participantes do estudo tinham características craniofaciais semelhantes e apresentavam mordida aberta anterior com o mesmo nível de comprometimento dentário e esquelético. As mudanças esqueléticas foram semelhantes em ambos os métodos de tratamento, bem como demonstraram grande aumento da sobremordida em relação aos pacientes não tratados. Após o período de tratamento, $82,2 \%$ das crianças que utilizaram o Quad Helix e a grade palatina corrigiram a má-oclusão, seguido por $86,4 \%$ das crianças que usaram o arco palatino com capacete de alta tração e protetor labial. 50\% das crianças não tratadas, tiveram correção espontânea da mordida aberta anterior.

Por outro lado, Nascimento et al., (2016) descreveram um caso clínico de tratamento de uma mordida aberta anterior grave causada por sucção digital e posicionamento anormal da língua em uma criança de 6 anos de idade. O paciente apresentou uma sobremordida negativa de $9 \mathrm{~mm}$ e $6 \mathrm{~mm}$ de overjet, além disso, possuía estrutura esquelética normal. Para o tratamento desse caso, foi utilizado um arco palatino fixo com esporões anteriores por 10 meses, suficiente para cessar o hábito de sucção digital. Também foi colocada uma grade palatina removível para reposicionar a língua, finalizando o tratamento 
interceptativo após 23 meses, exibindo um adequado alinhamento e nivelamento dos arcos, e corrigindo a sobremordida e o overjet observados anteriormente. Nesse caso, não foi necessário realizar tratamento complementar posterior com aparelhos fixos convencionais, demonstrando estabilidade do tratamento precoce.

Por sua vez, Rossato et al., (2018) compararam os efeitos dento-alveolares provocados pelo tratamento de mordidas abertas em crianças fazendo uso de esporões linguais colados, mentoneiras, grade palatina fixa e removível. Os participantes desse estudo exibiram uma sobremordida negativa média de $-3,7 \mathrm{~mm}$. Os tratamentos com esporões colados apresentaram uma redução na mordida aberta inicial de $-4,03 \mathrm{~mm}$ para $-0,94 \mathrm{~mm}$, em média. Já o uso de mentoneiras reduziu, em média, de $-3,88$ mm para $-1,62 \mathrm{~mm}$. A grade palatina fixa diminuiu a má-oclusão de $-3,31 \mathrm{~mm}$ para $-0,29 \mathrm{~mm}$, e a grade palatina removível passou de $-3,66 \mathrm{~mm}$ para $-0,34 \mathrm{~mm}$. Desse modo, todos os tratamentos apresentaram mudanças significativas na diminuição da mordida aberta, aumentando a sobremordida em 3,1 mm, em média. Somente os pacientes tratados com mentoneiras e grades palatinas fixas e removíveis exibiram extrusão dos molares inferiores. Nenhum dano sério ocorreu durante o tratamento das crianças, sendo relatado somente perdas ou quebras dos aparelhos, que não afetaram o desempenho do tratamento.

Mais tarde, Rossato et al., (2021) estudaram a ocorrência de complicações clínicas pelo uso de esporões colados, mentoneiras, grade palatina fixa e removível no tratamento de mordidas abertas anteriores. Após um tratamento de 12 meses, nenhuma diferença estatística significante foi encontrada entre os métodos de tratamento, e todos os protocolos foram considerados eficazes para corrigir a mordida aberta anterior. Durante a avaliação, 33,3\% dos pacientes não apresentaram nenhum tipo de complicação, sendo a maioria dos casos de complicações advindas do tratamento com os esporões colados, seguido pelo tratamento com mentoneiras e, por fim, com as grades palatinas removíveis e fixas, respectivamente. Somente $8 \%$ dos pacientes que fizeram uso dos esporões, não experimentaram qualquer complicação clínica. $\mathrm{O}$ uso dos esporões e das grades palatinas removíveis não causaram alergias ou lesões nos tecidos moles. Já as mentoneiras demonstraram ocorrência de alergia e as grades palatinas fixas mostraram $12 \%$ de prevalência de casos com lesões nos tecidos orais. Ocorreram 18 abandonos de tratamento, sendo mais frequentes nos grupos de aparelhos removíveis (mentoneira e grade palatina removível).

Já Torres et al., (2012) estudaram os efeitos dento-alveolares produzidos pelo tratamento de mordida aberta anterior com grade palatina fixa e removível, associados ao uso de mentoneiras, em crianças. Os participantes do estudo tinham características esqueléticas semelhantes, independente do tratamento utilizado, e nenhum dos dois protocolos demonstraram diferenças nessas medidas esqueléticas após 1 ano de uso dos aparelhos. Já as alterações dento-alveolares mostraram que o uso de grades removíveis apresentou maiores reduções no overjet e maior inclinação dos incisivos superiores, sendo que as grades fixas demonstraram maiores extrusões dos incisivos, que resultou em uma maior correção da sobremordida negativa, quando comparado ao outro protocolo de tratamento.

Por fim, Vasconcelos et al., (2020) avaliaram os efeitos do uso de arco de extrusão para o tratamento precoce de mordidas abertas anteriores. O tratamento resultou em diminuições significativas do perímetro e comprimento do arco, e também ocorreu uma diminuição média de $1,65 \mathrm{~mm}$ do overjet. A sobremordida inicial dos pacientes foi de $-1,28 \mathrm{~mm}$, passando a ser 1,79 mm após o período de tratamento, acarretando em um aumento de 3,07 $\mathrm{mm}$ na sobremordida. Além disso, também houve uma significativa extrusão dos incisivos superiores, com média de 1,94 mm durante o uso do aparelho. Essas mudanças dento-alveolares aconteceram em um período de tratamento de 7,79 meses. 
Tabela 1 - Características e dados dos artigos selecionados.

\begin{tabular}{|c|c|c|}
\hline $\begin{array}{c}\text { Autor/ } \\
\text { Ano }\end{array}$ & Amostra & Principais dados encontrados \\
\hline $\begin{array}{l}\text { Albogha et } \\
\text { al., } 2015\end{array}$ & $\begin{array}{l}30 \text { pacientes entre } \\
8 \text { e } 14 \text { anos. }\end{array}$ & $\begin{array}{l}\text { Os procedimentos foram efetivos na melhora ou no total } \\
\text { fechamento de mordidas abertas e apresentaram prejuízos } \\
\text { à higiene oral das crianças durante o tratamento, } \\
\text { necessitando de cuidados especiais na higienização. }\end{array}$ \\
\hline $\begin{array}{l}\text { Canuto et } \\
\text { al., } 2016\end{array}$ & 68 pacientes. & $\begin{array}{l}\text { Os tratamentos com esporões colados tiveram aceitação } \\
\text { maior do que os convencionais, principalmente durante a } \\
\text { alimentação e mastigação. O desconforto foi de } 7 \text { dias, e a } \\
\text { sobremordida positiva foi alcançada em } 16 \text { dos } 20 \text { casos e } \\
\text { em } 16 \text { dos } 21 \text { casos de pacientes que usaram esporão } \\
\text { colado e convencional, respectivamente, durante } 12 \text { meses } \\
\text { de tratamento. Também foi visto três casos de correção } \\
\text { espontânea da mordida aberta anterior. }\end{array}$ \\
\hline $\begin{array}{l}\text { Dias et al., } \\
2019\end{array}$ & $\begin{array}{c}01 \text { paciente de } 8 \\
\text { anos. }\end{array}$ & $\begin{array}{l}\text { O tratamento com os esporões demonstrou uma } \\
\text { sobremordida positiva cinco meses após o início do uso } \\
\text { do aparelho. Após } 2,15 \text { anos de tratamento as arcadas } \\
\text { dentárias estavam alinhadas com sobremordida normal e } \\
\text { irrupção adequada dos dentes permanentes. }\end{array}$ \\
\hline $\begin{array}{l}\text { Dyck et } \\
\text { al., } 2016\end{array}$ & $\begin{array}{l}22 \text { crianças com } \\
\text { idade de } 7 \text { a } 10 \\
\text { anos. }\end{array}$ & $\begin{array}{l}\text { Ocorreu um aumento da postura fisiológica da língua em } \\
\text { repouso e na deglutição após a terapia miofuncional. Após } \\
6 \text { meses do fim da terapia, essas crianças apresentaram } \\
\text { contato entre os incisivos inferiores e os seus antagônicos } \\
\text { ou com o palato em si. }\end{array}$ \\
\hline
\end{tabular}

$\begin{array}{lc}\text { Ferreira et } & 38 \text { crianças com } \\ \text { al., 2012 } & \text { idade média de } 9 \\ \text { anos. }\end{array}$
anos.

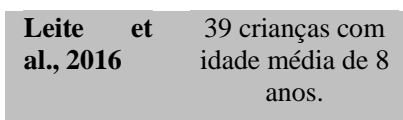

Lione et 34 pacientes com al., 2020 média de idade de 8 anos.

$\begin{array}{lc}\text { Mousa et } & \begin{array}{c}40 \text { crianças com } \\ \text { al., 2021 }\end{array} \\ \begin{array}{c}\text { idade média de } \\ 8,7 \text { anos. }\end{array}\end{array}$

Ambos os tratamentos duraram em média um ano para que fosse alcançada uma sobremordida positiva. Também se notou que 12 crianças tratadas com expansão rápida 11 tratadas com Quad Helix necessitaram de uma segunda fase de tratamento com aparelhos ortodônticos fixos convencionais.

Crianças tratadas com Bionator de mordida aberta tiveram maior valor de aumento, com 4,91 mm, em comparação ao uso do plano de mordida posterior removível com suporte de língua, com 3,43 mm. Apesar disso, as duas modalidades analisadas produziram alterações esqueléticas semelhantes.
Os blocos de mordida magnéticos apresentam melhores resultados em mordidas abertas com relações intermaxilares de classe II e protusão dos incisivos superiores.

Ambos os tratamentos produziram sobremordida positiva semelhante durante o tratamento da mordida aberta, sendo que os esporões colados tiveram maior aceitação, e $92,5 \%$ das crianças se ajustaram ao tratamento após uma semana.

O tratamento da mordida aberta anterior é um desafio, mas oferece um bom resultado e melhora a qualidade de vida dos pacientes. É uma má oclusão que requer um diagnóstico e tratamento precoce para interceptar os fatores etiológicos e obter estabilidade dos resultados do tratamento a longo prazo.

A terapia miofuncional pode influenciar positivamente o comportamento da língua, necessitando maiores estudos que possam comprovar esses resultados e esclarecer o uso dessa terapia como auxiliar para o tratamento ortodôntico de mordidas abertas anteriores.

O tratamento de mordida aberta anterior em dentição mista com o aparelho removível com grade palatina associado ao suporte para queixo de alta tração promoveu uma estabilidade dentária e esquelética de $95 \%$.

As grades palatinas e os esporões linguais colados juntos ao uso de mentoneiras foram eficazes para $o$ tratamento de mordidas abertas anteriores em crianças. Porém, o uso sozinho dessas mentoneiras não produziu tantos efeitos favoráveis quantos às associações.

O uso de grades palatinas fixas foi considerado eficaz para o tratamento precoce de mordida aberta anterior em $100 \%$ dos pacientes, e os esporões linguais colados resultaram em reversão da má-oclusão em 53,8\% dos pacientes após um período de um ano. Instruir e motivar a remoção de hábitos deletérios pode resultar em correção espontânea da mordida aberta, apesar de isso ocorrer com uma frequência muito baixa.

Expansão rápida da maxila e bloqueios de mordida proporcionaram mudanças significativas na orientação vertical esquelética e do ramo mandibular, corrigindo a mordida aberta anterior esquelética dos pacientes tratados.

Ambos os métodos de tratamento proposto foram eficazes para o tratamento precoce de mordidas abertas anteriores esqueléticas. O principal fator associado ao fechamento da mordida aberta foi a alteração dento-alveolar das arcadas. 


\begin{tabular}{|c|c|c|c|}
\hline $\begin{array}{l}\text { Mucedero } \\
\text { et al., } 2017\end{array}$ & $\begin{array}{l}70 \text { crianças em } \\
\text { idade média de } 8 \\
\text { anos. }\end{array}$ & $\begin{array}{l}82,2 \% \text { das crianças que utilizaram o Quad Helix e a grade } \\
\text { palatina corrigiram a má-oclusão, seguido por } 86,4 \% \text { das } \\
\text { crianças que usaram o arco palatino com capacete de alta } \\
\text { tração e protetor labial. } 50 \% \text { das crianças não tratadas, } \\
\text { tiveram correção espontânea da mordida aberta anterior. }\end{array}$ & $\begin{array}{l}\text { Ambos os tratamentos apresentaram } \\
\text { eficácia semelhante na correção da } \\
\text { mordida aberta, com altas taxas de } \\
\text { correção da má-oclusão, em } \\
\text { comparação aos casos de resolução } \\
\text { espontânea, sem tratamento. }\end{array}$ \\
\hline $\begin{array}{l}\text { Nasciment } \\
0 \text { et al., } \\
2016\end{array}$ & $\begin{array}{c}01 \text { crianças com } 6 \\
\text { anos de idade. }\end{array}$ & $\begin{array}{l}\text { Utilização de um arco palatino fixo com esporões } \\
\text { anteriores por } 10 \text { meses, para cessar o hábito de sucção } \\
\text { digital, e uma grade palatina removível para reposicionar } \\
\text { a língua, finalizando o tratamento interceptativo após } 23 \\
\text { meses, com adequado alinhamento e nivelamento dos } \\
\text { arcos, e corrigindo a sobremordida e o overjet. }\end{array}$ & $\begin{array}{l}\text { O diagnóstico correto e uma } \\
\text { abordagem clínica simples e eficiente } \\
\text { são fatores imprescindíveis para um } \\
\text { tratamento de qualidade da mordida } \\
\text { aberta anterior. }\end{array}$ \\
\hline $\begin{array}{l}\text { Rossato et } \\
\text { al., } 2018\end{array}$ & $\begin{array}{l}81 \text { crianças entre } \\
7 \text { e } 10 \text { anos. }\end{array}$ & $\begin{array}{l}\text { Os participantes desse estudo exibiram uma sobremordida } \\
\text { negativa média de }-3,7 \text { mm. Todos os tratamentos } \\
\text { apresentaram mudanças significativas na diminuição da } \\
\text { mordida aberta, aumentando a sobremordida em } 3,1 \mathrm{~mm} \text {, } \\
\text { em média. Somente os pacientes tratados com } \\
\text { mentoneiras e grades palatinas fixas e removíveis } \\
\text { exibiram extrusão dos molares inferiores. }\end{array}$ & $\begin{array}{l}\text { Todos os tratamentos foram eficazes } \\
\text { na redução da mordida aberta em } \\
97,5 \% \text { das crianças do estudo, porém, } \\
\text { somente } 47 \% \text { delas obtiveram } \\
\text { sobremordida positiva após } 12 \text { meses } \\
\text { de tratamento. A grade palatina fixa } \\
\text { produziu o maior impacto no } \\
\text { posicionamento dos incisivos, sendo } \\
\text { uma boa escolha para o tratamento da } \\
\text { má-oclusão. }\end{array}$ \\
\hline $\begin{array}{l}\text { Rossato et } \\
\text { al., } 2021\end{array}$ & $\begin{array}{l}99 \text { crianças com } \\
\text { idade média de } \\
8,4 \text { anos. }\end{array}$ & $\begin{array}{l}33,3 \% \text { dos pacientes não apresentaram nenhum tipo de } \\
\text { complicação, sendo a maioria dos casos de complicações } \\
\text { advindas do tratamento com os esporões colados, seguido } \\
\text { pelo tratamento com mentoneiras e, por fim, com as } \\
\text { grades palatinas removíveis e fixas, respectivamente. }\end{array}$ & $\begin{array}{l}\text { O uso de esporões colados apresentou } \\
\text { maior frequência de complicações } \\
\text { clínicas. Não existem diferenças de } \\
\text { complicações entre aparelhos fixos e } \\
\text { removíveis, apesar de os removíveis } \\
\text { terem um maior número de abandono } \\
\text { do tratamento. }\end{array}$ \\
\hline $\begin{array}{l}\text { Torres et } \\
\text { al., } 2012\end{array}$ & $\begin{array}{l}60 \text { crianças com } \\
\text { idade média de } 8 \\
\text { anos. }\end{array}$ & $\begin{array}{l}\text { Grades removíveis apresentaram maiores reduções no } \\
\text { overjet e maior inclinação dos incisivos superiores. } \\
\text { Grades fixas demonstraram maiores extrusões dos } \\
\text { incisivos e uma maior correção da sobremordida negativa. }\end{array}$ & $\begin{array}{l}\text { As grades palatinas fixas associadas } \\
\text { ao uso de mentoneiras foram mais } \\
\text { eficazes na correção da mordida } \\
\text { aberta anterior. Porém, as grades } \\
\text { removíveis apresentaram um melhor } \\
\text { posicionamento dos incisivos e maior } \\
\text { correção do overjet. }\end{array}$ \\
\hline $\begin{array}{l}\text { Vasconcel } \\
\text { os et al., } \\
2020\end{array}$ & 14 crianças. & $\begin{array}{l}\text { Ocorreu uma diminuição média de } 1,65 \mathrm{~mm} \text { do overjet. A } \\
\text { sobremordida inicial dos pacientes foi de }-1,28 \mathrm{~mm} \text {, } \\
\text { passando a ser } 1,79 \mathrm{~mm} \text { após o período de tratamento, } \\
\text { acarretando em um aumento de } 3,07 \mathrm{~mm} \text { na } \\
\text { sobremordida. Houve uma significativa extrusão dos } \\
\text { incisivos superiores, com média de } 1,94 \mathrm{~mm} \text { durante o } \\
\text { uso do aparelho por } 7,79 \text { meses. }\end{array}$ & $\begin{array}{l}\text { O arco de extrusão produziu o } \\
\text { fechamento da mordida aberta em } \\
\text { todos os pacientes em um tempo } \\
\text { médio de } 7,79 \text { meses, e também } \\
\text { proporcionou uma diminuição do } \\
\text { overjet. }\end{array}$ \\
\hline
\end{tabular}

Fonte: Elaborado pelos autores (2021)

\section{Discussão}

Os estudos demonstraram que existem inúmeros aparelhos, dispositivos, bem como associações de protocolos de tratamentos que podem ser usados com sucesso para o tratamento precoce da mordida aberta anterior, resultando em melhorias, e até mesmo na correção dessa má-oclusão em específico. Grande parte dos casos de mordidas abertas anteriores dentoalveolares foram associados aos hábitos bucais deletérios, sobretudo aos de sucção não nutritiva. Alguns dos casos abordados foram autocorrigidos com a retirada dos estímulos danosos. Porém, na maioria dos casos, as crianças não conseguiam eliminar os hábitos sem a intervenção de aparelhos ortodônticos, bem como as consequentes modificações nas estruturas dentoalveolares não sofreram autocorreção, sendo necessário o estabelecimento de abordagens terapêuticas que estabelecessem o posicionamento correto da língua durante o repouso, proporcionando o fechamento e o ajuste do posicionamento dentário dos incisivos. Esses casos em que as intervenções foram necessárias ocorreram em crianças entre 6 e 10 anos, e foi considerada uma boa faixa etária para abordar o tratamento das mordidas abertas anteriores.

Uma forma de intervenção que auxilia na eliminação dos hábitos deletérios diz respeito ao uso de esporões linguais, colados ou removíveis. Eles funcionam auxiliando na postura correta da língua, impedindo um posicionamento muito anterior que impulsionaria os incisivos para frente, causando a mordida aberta. Esse método exibiu bons resultados quanto ao aumento da sobremordida,e na grande maioria dos casos, gerou o fechamento completo da mordida aberta, com sobremordida positiva 
em até 12 meses de tratamento. Além disso, foi considerado um tratamento de boa aceitação e adaptação por parte das crianças, principalmente quando se fez uso dos esporões colados, sendo mais práticos ao eliminar procedimentos de bandagem e outas fases laboratoriais necessárias em aparelhos removíveis. (Canuto et al., 2016; Dias et al., 2019). Por sua vez, Nascimento et al., 2016 demonstrou uma associação entre a utilização de esporões linguais junto a um arco palatino fixo, com o objetivo de realizar uma expansão maxilar para complementar o tratamento e proporcionar um maior aumento da sobremordida em casos mais graves, demonstrando que, a depender do caso, associações são feitas para restabelecer a erupção fisiológica dos incisivos.

Outros dispositivos também são amplamente empregados para ajudar na eliminação dos hábitos deletérios e na reposição adequada da língua, sendo inquestionável a boa atuação das grades palatinas fixas e removíveis, e das mentoneiras. Os estudos demonstraram que tanto essas duas abordagens, bem como o próprio uso dos esporões linguais fornecem uma boa média de aumento em sobremordidas, sendo que a utilização de grades palatinas demonstrou maiores aumentos na sobremordida, quando comparado ao uso de esporões, e que as grades palatinas fixas proporcionaram maiores valores médios na sobremordida, em relação às removíveis devido a uma maior extrusão dos incisivos. Os esporões linguais, por sua vez, demonstraram melhores resultados em relação à utilização de mentoneiras. Essa superioridade das grades palatinas se deve provavelmente ao fato de possuir uma área maior para obstrução da projeção anterior da língua e da introdução de dedos e chupetas na cavidade oral. Porém, essa forma de tratamento possui a desvantagem de necessitar de um maior tempo clínicos, maiores despesas laboratoriais e menor aceitação inicial do paciente pela imediata alteração na fala. (Leite et al., 2016; Rossato et al., 2018; Torres et al., 2012).

Além dessas intervenções para o tratamento das mordidas abertas dento-alveolares, outras também são elencadas como protocolos eficientes nesses casos específicos. Albogha et al., (2015) evidenciaram efeitos positivos na melhora, e em muitos casos, no fechamento total das mordidas abertas anteriores através do uso de blocos de mordida magnéticos e aparelhos de intrusão rápida de molares junto a bloqueios de mordida posteriores. Os blocos de mordida controlaram a altura dentoalveolar através da intrusão e interrupção da irrupção dos molares superiores, e os aparelhos de intrusão rápida dos molares utilizaram molas helicoidais para intruir os elementos dentários. Contudo, esses dois modelos demonstraram prejuízos na higiene oral das crianças. Já Vasconcelos et al., (2020) mostraram um considerável aumento da sobremordida com consequente fechamento da mordida aberta através da utilização de arcos de extrusão, gerando forças extrusivas nos incisivos superiores. E, além da abordagem ortodôntica através dos aparelhos e dispositivos interceptativos, Dyck et al., (2016) relataram melhorias na postura fisiológica da língua através de um tratamento por terapia miofuncional, permitindo a irrupção fisiológica dos elementos dentários permanentes.

Já foi comprovado que as intervenções com os aparelhos e dispositivos são eficazes para o tratamento precoce da mordida aberta anterior. Porém, nos casos em que essa má-oclusão possui envolvimento esquelético, além do dento-alveolar, o emprego isolado desses métodos de tratamento nem sempre causam grandes modificações nos padrões de mordida, sendo necessária a associação de aparelhos, com o objetivo de melhorar os resultados e possibilitar uma estabilização da mordida, que é instável nos casos de mordidas abertas anteriores dento-esqueléticas. Assim, a aplicação de grades palatinas fixas e removíveis em conjunto com as mentoneiras foram consideradas boas opções para a abordagem terapêutica precoce da mordida aberta, eliminando, na grande maioria dos casos a presença de sobremordida negativa, e ainda viabilizando uma boa estabilidade após o restabelecimento fisiológico da mordida nas crianças. (Torres et al., 2012; Ferreira et al., 2012).

As grades palatinas também foram usadas em conjunto ao Quad Helix, que causa uma rotação do plano palatino, para o tratamento das mordidas abertas anteriores esqueléticas, além aparelhos de expansão rápida da maxila com bloqueios de mordida, arcos palatinos de expansão associados a capacetes de alta tração com protetor labial, o Bionator de mordida aberta, e o plano de mordida posterior removível com suporte de língua. Todos esses protocolos de tratamentos foram considerados 
eficientes na abordagem terapêutica precoce das mordidas abertas, acarretando em um consistente aumento da sobremordida, correção das alterações esqueléticas presentes, e estabilidade das funções fisiológicas recém-estabelecidas. O Quad Helix associado com a grade palatina produziram os melhores resultados em relação às modificações esqueléticas verticais, produzindo um fechamento da mordida aberta mais fisiológico e maior estabilidade das modificações a longo prazo. Além disso, o Bionator e o plano de mordida posterior exibiram casos de irritação da mucosa oral. (Lione et al., 2020; Mucedero et al., 2017; Mousa et al., 2021).

Por fim, nenhum desses protocolos de tratamento relataram casos de complicações durante os procedimentos clínicos que prejudicassem a qualidade e a eficiência da ação efetuada por esses aparelhos durante todas as etapas de tratamento. Entretanto, a utilização de esporões linguais colados apresentou o maior número de casos de pequenos inconvenientes, como perda, descolamento de peças, machucados na língua e mucosas. Além disso, os aparelhos considerados removíveis foram os que mais sofreram abandono de tratamento por causa da baixa cooperação dos pacientes. Com base em todas essas considerações, é parte da atribuição do profissional da odontologia considerar as relações custo-benefício, bem como os fatores etiológicos envolvidos na má-oclusão, e o grau de comprometimento e cooperação das crianças para indicar de forma correta o modelo de tratamento que obterá os melhores resultados para cada caso em específico, podendo empregar aparelhos fixos, removíveis e associações de ambos, dependendo das vantagens obtidas ao final do plano de tratamento. (Rossato et al., 2021).

\section{Conclusão}

A mordida aberta anterior é uma má-oclusão multifatorial que pode acometer as estruturas dentárias e esqueléticas, sendo usualmente associadas ao desenvolvimento de hábitos bucais deletérios. É uma condição de difícil tratamento que geralmente resulta em recidivas. A eliminação do hábito deletério é o principal objetivo do tratamento precoce das mordidas abertas anteriores, e para isso são empregadas inúmeras intervenções, baseadas no uso de aparelhos ortodônticos fixos, removíveis e associações de mais de um dispositivo. Esses métodos de tratamento são bastante eficazes na diminuição da sobremordida negativa, ocasionando na grande maioria dos casos estudados, o fechamento da mordida aberta anterior. Além disso, esses aparelhos proporcionam uma boa estabilidade a longo prazo, após o restabelecimento fisiológico da posição da língua, dos elementos dentários e das alterações esqueléticas obtidas, sem causar graves complicações durante as sessões de tratamento.

\section{Referências}

Albogha, H., Takahashi, I., \& Sawan, N. (2015). Early treatment of anterior open bite: Comparison of the vertical and horizontal morphological changes induced by magnetic bite-blocks and adjusted rapid molar intruders. Korean J Orthod, 45 (1), 38-46.

Artese, A., Drummond, S., Nascimento, J. M., \& Artese, F. (2011). Critérios para o diagnóstico e tratamento estável da mordida aberta anterior. Dental Press J Orthod, 16 (3), 136-161.

Canuto, L. F., Janson, G., Lima, N. S., Almeida, R. R., \& Cançado, R. H. (2016). Anterior open-bite treatment with bonded vs conventional lingual spurs: A comparative study. American Journal of Orthodontics and Dentofacial Orthopedics, 149 (6), 847-855.

Dias, F. A., Urnau, F. D. A., Oltramari, P. V. P., Poleti, M. L., Almeida, M. R., \& Fernandes, T. M. F. (2019). Stability of early treatment of anterior open bite: clinical performance of bonded lingual spurs. Journal of Orthodontics, 46 (1) 68-73.

Dyck, C. V., Dekeyser, A., Vantricht, E., Manders, E., Goeleven, A., Fieuws, S., \& Willems, G. (2016). The effect of orofacial myofunctional treatment in children with anterior open bite and tongue dysfunction: a pilot study. European Journal of Orthodontics, 39 (3), $227-234$.

Ferreira, F. P. C., Almeida, R. R., Torres, F. C., Almeida-Pedrim, R. R., Almeida, M. R., \& Santana Filho, R. (2012). Evaluation of the stability of open bite treatment using a removable appliance with palatal crib combined with high-pull chincup. Dental Press J Orthod., 17 (6), $52-60$.

Hermont, A. P., Zina, L. G., Silva, K. D., Silva, J. M., \& Martins-Júnior, P. A. (2021). Revisões integrativas: conceitos, planejamento e execução. Arq Odontol, 57 (1), 3-7.

Insabralde, N. M., Almeida, R. R., Henriques, J. F. C., Fernandes, T. M. F., Flores-Mir, C., \& Almeida, M. R. (2016). Dentoskeletal effects produced by removable palatal crib, bonded spurs, and chincup therapy in growing children with anterior open bite. Angle Orthodontist, 86 (6), $969-975$. 
Koletsi, D., Makou, M., \& Pandis, N. (2018). Effect of orthodontic management and orofacial muscle training protocols on the correction of myofunctional and myoskeletal problems in developing dentition. A systematic review and meta-analysis. Orthod Craniofac Res., 1 (1), 1-14.

Leite, J. S., Matiussi, L. B., Salem, A. C., Provenzano, M. G. A., \& Ramos, A. L. (2016). Effects of palatal crib and bonded spurs in early treatment of anterior open bite: A prospective randomized clinical study. Angle Orthodontist, 86 (5), 734-739.

Lione, R., Fusaroli, D., Mucedero, M., Paoloni, V., Pavoni, C., \& Cozza, P. (2020). Changes in mandibular shape after early treatment in subjects with open bite: a geometric morphometric analysis. European Journal of Orthodontics, 1 (1), 1-7.

Moher, D., Liberati, A., Tetzlaff, J., Altman, D. G., \& The PRISMA Group. (2009). Preferred Reporting Items for Systematic Reviews and Meta-Analyses: The PRISMA Statement. Plos Medicine, 6 (7), 1-6.

Mousa, M. R., Hajeer, M. Y., \& Farah, H. (2021). Evaluation of the open-bite Bionator versus the removable posterior bite plane with a tongue crib in the early treatment of skeletal anterior open bite: a randomized controlled trial, Journal of the World Federation of Orthodontists, 1 (1), 1-9.

Mucedero, M., Vitale, M., Franchi, L., Cozza, P., \& Perillo, L. (2017). Comparisons of two protocols for early treatment of anterior open bite. European Journal of Orthodontics, 1 (1), 270-276.

Nascimento, M. H. A., Araújo, T. M., \& Machado, A. W. (2016). Severe Anterior Open Bite during Mixed Dentition Treated with Palatal Spurs. The Journal of Clinical Pediatric Dentistry, 40 (3), 247-250.

Núñez, F. B., Rodríguez, L. R., Mileo, M. J., \& Schemann-Miguel, F. (2014). Aporte del Pediatra en la Prevención de la Mordida Abierta Anterior. Archivos Venezolanos De Puericultura Y Pediatría, 77 (1), 24-28.

Pisani, L., Bonaccorso, L., Fastuca, R., Spena, R., Lombardo, L., \& Caprioglio, A. (2016). Systematic review for orthodontic and orthopedic treatments for anterior open bite in the mixed dentition. Progress in Orthodontics, 1 (1), 1-14.

Rosa, M., Quinzi, V., \& Marzo, G. (2019). Paediatric Orthodontics Part 1: Anterior open bite in the mixed dentition. European Journal of Paediatric Dentistry, 20 (1), 80-82.

Rossato, P. H., Fernandes, T. M. F., Urnau, F. D. A., Conti, A. C. C. F., Almeida, R. R., \& Oltramari-Navarro, P. V. P. (2018). Dentoalveolar effects produced by different appliances on early treatment of anterior open bite: A randomized clinical trial. Angle Orthod., 88 (1), $684-691$.

Rossato, P. H., Bayer, L. B., Almeida, R. R., Conti, A. C. C. F., Fernandes, T. M. F., \& Oltramari, P. V. P. (2021). Clinical complications during early treatment of anterior open bite. Braz. Oral Res., 35 (81), 1-7.

Torres, F. C., Almeida, R. R., Almeida-Pedrin, R. R., Pedrin, F., \& Paranhos, L. R. (2012). Dentoalveolar comparative study between removable and fixed cribs, associated to chincup, in anterior open bite treatment. J Appl Oral Sci., 1 (1), 531-537.

Vasconcelos, J. B., Almeida-Pedrin, R. R., Poleti, T. M. F. F., Oltramani, P., Conti, A. C. F. C., Bicheline, M. H. B., Lindauer, S. J., \& Almeida, M. R. (2020). A prospective clinical trial of the effects produced by the extrusion arch in the treatment of anterior open bite. Progress in Orthodontics, 21 (39), 1-8. 